\title{
A RESEARCH ON DIGITAL TECHNOLOGY'S APPLICATION IN PRESERVATION PLANNING OF WENMING HISTORICAL AND CULTURAL BLOCK IN KUNMING
}

\author{
Xiaowei Huo ${ }^{\text {a }}$, Yecheng Liu ${ }^{\text {a }}$, Gong Zhang ${ }^{\text {a }}$, Haoyu Yang ${ }^{\text {b }}$
}

\author{
${ }^{a}$ Beijing Tsinghua Tongheng Urban Planning and Design Institute, Research Center for Historical and Cultural City, \\ W1900, Building Jia1 East Qinghe Jiayuan, Haidian District, Beijing, China \\ ${ }^{\mathrm{b}}$ East dawn Corporation, Survey Center - Division 2, Haidian District, Beijing,China
}

KEY WORDS: Historical and cultural block, Preservation planning, Digital recording, Dynamic monitoring and management, Mobile GIS technology, 3D laser scanning

\begin{abstract}
:
The preservation of traditional settlements plays an indispensable part in the field of heritage preservation. The traditional settlements, definitely with cumulative developmental layers, vary in elements and involving numerous stakeholders; therefore, preservation objects and methods are quite complicated. The traditional heritage investigating and recording tools, such as manual mapping, photographing and field reconnaissance, which have exposed many limitations and deficiencies in the actual work, have defects to meet the requirements of settlement heritage preservation projects. This paper describes the process of applying of modern digital heritage recording and investigation technology (mobile GIS and 3D laser scanning technology) in the preservation of Wenming historical and cultural blocks in Kunming and argues that Mobile GIS and 3D laser scanning technology are capable of producing a complete and efficient workflow, as well as providing fundamental technical support for heritage preservation work. Through the research, this paper draws a conclusion that the advantages of the workflow including: (1) accurate and convenient recording, (2) efficient comprehensive spatial analysing, and (3) better integrating protection planning with the later dynamic monitoring and management. Additionally, the author forecasts the prospects of the application of this workflow in the preservation and utilization of settlement heritage.
\end{abstract}

\section{INTRODUCTION}

In China, where there is an ancient civilization of five thousand years, distributes not only historical relics like historic structures and sites, but also abundant historic settlement. Ever since 1950s, Chinese government has gradually founded a comprehensive heritage preservation system, which refers to different types of cultural heritages, such as immovable heritage, historic cities, historic towns and historical blocks and so on. (Ruan, 1999)

Historical and cultural block, as an important aspect of Chinese settlements preservation, is an essential existence of urban history and culture, and, relying on its distinctive value in art, science and humanity, it keeps on developing with the long history of city. At the same time, historical and cultural block is a kind of precious recourse which is non-renewable, and most of them are experiencing poor preservation, decayed function, outdated facilities and other problems because of social vicissitudes and urban function changes. (Gong Zhang, 2012)

\section{WENMING BLOCKS--A MICROCOSM OF THE PRESERVATION AND SUPERVISION OF HISTORICAL AND CULTRAL BLOCKS IN CHINA}

Wenming historical and cultural block (22.66 hectares in all), situated at the central part of Kunming downtown, where distributes the Confucian temple, the victory of the AntiJapanese War memorial hall, the Fulin Hall and many other significant heritages, is one of the two remaining historical and cultural blocks of Kunming. The preserving and supervising problems reveal in Wenming historical and cultural blocks, which are caused by the out-dated recording technology, is the microcosm of historical and cultural blocks across China.

The information recording of historical and cultural block can be typically classified into two categories: (1) basic block information, include the style, quality, history, property right and so on, most of which are recorded manually in paper document; (2) surface and structure information of architecture, most of which are recorded by manual mapping and photographing. Traditional methods of information recording have exposed many limitations and deficiencies in the actual work.

\subsection{Low efficiency of basic information recording with omissions and errors}

Because the information recording on the field is by the means of paper, much work is needed to sort out data and match drawings manually. At the same time, the outcomes of information recording are only CAD drawings, Microsoft Word documents and paper documents, but not consolidated digital database, so the efficiency is always alternated by omissions and errors, and it is difficult for data searching and updating in the future. What's more, lacking of the effective photo correspondingly searching system, omissions and errors could not be easily found out. 


\subsection{Low accuracy of traditional mapping, without dynamic} monitoring

As the historical and cultural blocks form and keep on developing during a long history, the styles and features are varied. To a single architecture, because of repeated renovation and rebuilding, the integral structure and the details are diverse. In addition, given high integrity, high density, poor condition and narrow streets, there are actual difficulties in mapping.

As a result of the outcomes of traditional mapping are all static, it is difficult for the administrating and planning departments to monitor the effects of renovation, especially to track some of the key points in detail, so most of the styles and features are changed quite seriously after renovation, comparing with that before.

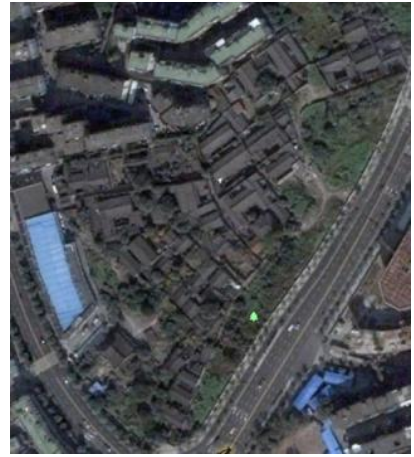

Figure 1. Remote sense image of Yujiaxiang historical and cultural block (before renovation, 2007)

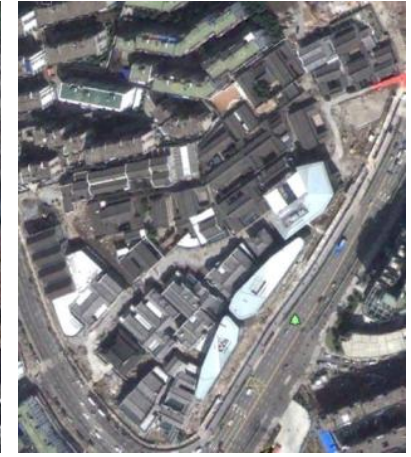

Figure 2. Remote sense image of Yujiaxiang historical and cultural block (after renovation, 2010)

\subsection{Limited application of recorded information, cannot support management}

As the outcomes of existing information recording of preservation planning are always separate paper documents, without digital database, it is difficult to share information, analyze the data and monitor in the later supervision. That's why the application of the recorded information is quite limited, failing in supporting the administration of blocks.

\subsection{The workflow of digital recording in the preservation of historical and cultural blocks}

In order to avoid all the problems above, GIS and 3D scanning technology are applied during the preservation of Wenming historical and cultural blocks, and the workflow of digital information recording in the preservation of historical and cultural blocks is as follows:

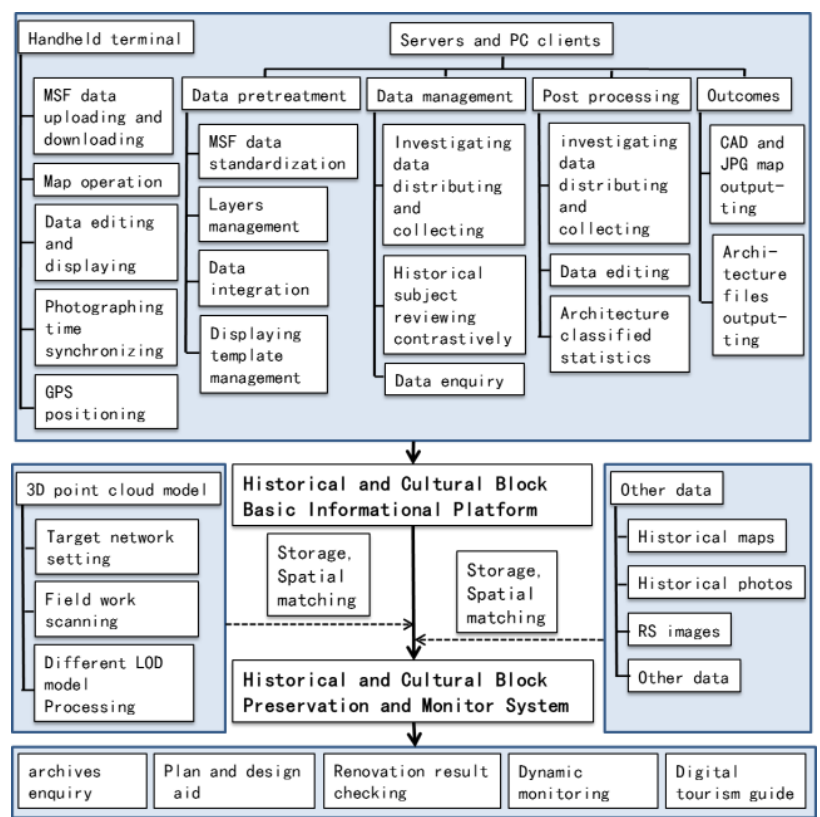

Figure 3. Digital information recording workflow of historical and cultural block

\section{GIS AND THE BASIC INFORMATION RECORDING SYSTEM OF HISTORICAL AND CULTURAL BLOCKS (BIRSHCB)}

\subsection{System frame and workflow}

The system, which is mainly composed by handheld terminals, servers and PC clients, is formed with both $\mathrm{C} / \mathrm{S}$ and $\mathrm{B} / \mathrm{S}$ and based on the platform of OpenWeb3S, which is developed by Sinoving (Beijing) Technique CO., Ltd. The data format of the system is compatible with ARCGIS, SuperMap and other widely used formats.

At present, iPAD (3G) is the basic platform of the handheld terminals, while Oracle is the database platform of servers. Based on this system, the traditional information recording of architectures and be reformed to the following workflow:

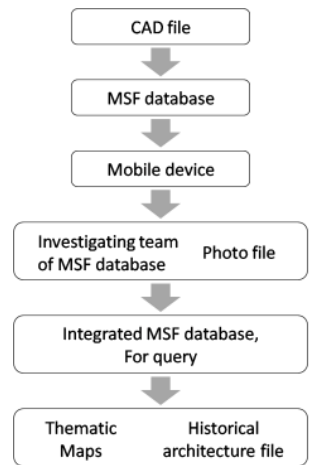

Figure 4. Workflow of BIRSHCB

\subsection{Main functional modules}

Table 1. Main functional modules of BIRSHCB

\begin{tabular}{|l|l|l|}
\hline modules & Functions & Specific application modes \\
\hline Data pre- & Vector data & After logging on to the server, \\
treatment & import and & projects can be started and edited, \\
and & export, MSF & and original terrain data (dwg \\
\hline
\end{tabular}




\begin{tabular}{|c|c|c|}
\hline $\begin{array}{l}\text { project } \\
\text { managem } \\
\text {-ent } \\
\text { modules } \\
\text { at the } \\
\text { servers }\end{array}$ & $\begin{array}{l}\text { data } \\
\text { standardizat } \\
\text {-ion and } \\
\text { storage, } \\
\text { layer } \\
\text { management } \\
\text { data zoning } \\
\text { integration }\end{array}$ & $\begin{array}{l}\text { format) can be imported. In the } \\
\text { data transformation table, data in } \\
\text { dwg format can be transformed in } \\
\text { quantity. And this function allows } \\
\text { that certain layers (such as } \\
\text { architectures, words, basic maps) } \\
\text { of CAD can be transformed to } \\
\text { MSF individual database. }\end{array}$ \\
\hline \multirow{4}{*}{$\begin{array}{l}\text { Handheld } \\
\text { terminal } \\
\text { modules }\end{array}$} & $\begin{array}{l}\text { Original } \\
\text { data } \\
\text { downloadin- } \\
\text { g, map } \\
\text { displaying } \\
\text { and editing }\end{array}$ & $\begin{array}{l}\text { Pre-treatment project database } \\
\text { can be downloaded to handheld } \\
\text { terminals from the servers, and } \\
\text { can be displayed, moved, } \\
\text { enlarged, shrink and processed in } \\
\text { other ways on the handheld } \\
\text { terminals. In particular, } \\
\text { architectures can be added or } \\
\text { deleted once they are found built } \\
\text { or removed during investigation. }\end{array}$ \\
\hline & $\begin{array}{l}\text { GPS } \\
\text { positioning } \\
\text { and } \\
\text { calibrating }\end{array}$ & $\begin{array}{l}\text { Investigators can use GPS } \\
\text { equipment to locate positions and } \\
\text { track boundaries in field. }\end{array}$ \\
\hline & $\begin{array}{l}\text { Thematic } \\
\text { maps } \\
\text { displaying } \\
\text { contrastivel- } \\
\text { y }\end{array}$ & $\begin{array}{l}\text { Maps of special subjects, like } \\
\text { style, quality and time, can } \\
\text { display separately, so that } \\
\text { investigators and supervisors can } \\
\text { review the state and style of the } \\
\text { surrounding architectures timely. }\end{array}$ \\
\hline & $\begin{array}{l}\text { Investigatin- } \\
\mathrm{g} \text { data } \\
\text { uploading }\end{array}$ & $\begin{array}{l}\text { After the investigating data have } \\
\text { been entered to the handheld } \\
\text { terminals, they can be uploaded to } \\
\text { the servers by equipment } \\
\text { connecting. }\end{array}$ \\
\hline \multirow{4}{*}{$\begin{array}{l}\text { Data post } \\
\text { treatment } \\
\text { and } \\
\text { outcomes } \\
\text { export } \\
\text { modules }\end{array}$} & $\begin{array}{l}\text { Photo } \\
\text { matching } \\
\text { and storing }\end{array}$ & $\begin{array}{l}\text { By matching the time of the } \\
\text { photos EXIF and that of the } \\
\text { investigating data, the system can } \\
\text { upload the photos to the database } \\
\text { automatically, and by doing so, } \\
\text { the supervisors can make better } \\
\text { comparisons among the photos in } \\
\text { the field. }\end{array}$ \\
\hline & $\begin{array}{l}\text { Database } \\
\text { displaying } \\
\text { and } \\
\text { enquiring }\end{array}$ & $\begin{array}{l}\text { Once selecting a architecture or a } \\
\text { yard, a table with all the relating } \\
\text { information and photos entered } \\
\text { will appear for any further } \\
\text { enquiry. As the exact photo has } \\
\text { displayed on the screen, the } \\
\text { administrators can examine all the } \\
\text { information conveniently and } \\
\text { correct mistakes immediately. }\end{array}$ \\
\hline & $\begin{array}{l}\text { Thematic } \\
\text { maps } \\
\text { displaying } \\
\text { and } \\
\text { outputting }\end{array}$ & $\begin{array}{l}\text { The software can display maps of } \\
\text { different subject, such as style, } \\
\text { quality, time and other } \\
\text { characteristics. Meanwhile, all the } \\
\text { maps can be output as CAD and } \\
\text { JPG documents, which mean the } \\
\text { real automatic output of } \\
\text { investigating outcomes. }\end{array}$ \\
\hline & $\begin{array}{l}\text { Historical } \\
\text { maps } \\
\text { displaying } \\
\text { and } \\
\text { enquiring }\end{array}$ & $\begin{array}{l}\text { The same as handheld terminal, } \\
\text { the software can display and } \\
\text { enquire maps of different time } \\
\text { contrastively, easy for the } \\
\text { supervisor to know well of any }\end{array}$ \\
\hline
\end{tabular}

\begin{tabular}{|l|l|l|}
\hline $\begin{array}{l}\text { contrastivel- } \\
\text { y }\end{array}$ & changes of the buildings. \\
\cline { 2 - 3 } $\begin{array}{l}\text { Statistical } \\
\text { analysis }\end{array}$ & $\begin{array}{l}\text { The software can assist make the } \\
\text { zoning decision, and show the } \\
\text { ration of every single different } \\
\text { type of the buildings within the } \\
\text { area selected, which is a powerful } \\
\text { tool for the supervisor to review } \\
\text { the whole situation of the } \\
\text { architectures. }\end{array}$ \\
\cline { 2 - 3 } $\begin{array}{l}\text { Historical } \\
\text { architecture } \\
\text { files export }\end{array}$ & $\begin{array}{l}\text { Different levers of buildings can } \\
\text { be output as different files, most } \\
\text { of the time in historical lever, and } \\
\text { coded separately. The format of } \\
\text { the output is Word, welcomed for } \\
\text { further adjustments and changes. }\end{array}$ \\
\hline
\end{tabular}
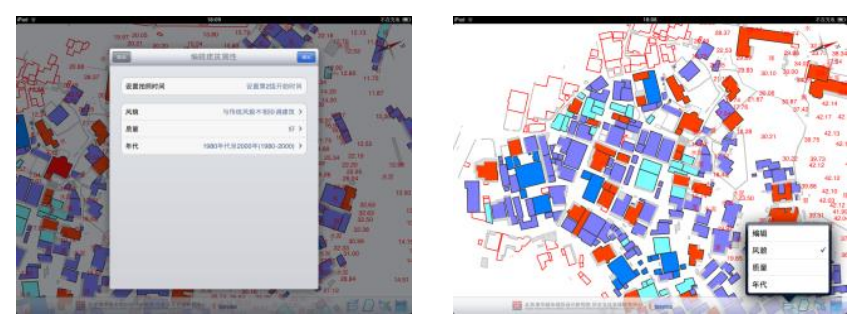

Figure 5. UI of handheld terminal

\section{3DLS AND 3D MODEL DATA RECORDING OF WENMING HISTORICAL AND CULTURAL BLOCK}

In recent years, 3DLS technology is extensively used in the field of international cultural heritage preservation, especially in digital records, virtual visualization display and dynamic monitoring. (Yan, 2012) When this technology was introduced to China, it was first used in the preservation of cultural relics such as Buddhist statues and grottoes. Authors of this paper, having been researching on the preservation of historical and cultural blocks for a long time, find that 3DLS technology could fill the gap of traditional techniques of photographing and manual building surveying used in the past, and apply the technology in the preservation of Wenming historical and cultural block in Kunming.

\subsection{Scanning Field Work}

4.1.1 Hardware equipment: The hardware equipment include $\mathrm{Z}+\mathrm{F}$ scanner, the world famous one-man operation 3DLS scanner, the Riegl 3D laser scanner, the 5D Mark II and the 60D digital single-lens reflex (SLR) cameras. The Z+F scanner and the Riegl 3D laser scanner are used to capture the point cloud data of the districts and heritage buildings, while 5D Mark II and 60D digital single-lens reflex (SLR) camera are used to collect the image texture information. 
4.1.2 Setting Up Temporary Target Network: Using paper target reflection, the temporary target network is mainly arranged in the following locations: fixed walls of historical buildings, permanent walls the buildings along the street such as gable walls and fire walls, renovated buildings and new buildings around the districts. The height of target should be set at a high position and for the scanning of the roof structure; the scanning platform should be not more than $50 \mathrm{~m}$ away from the target.

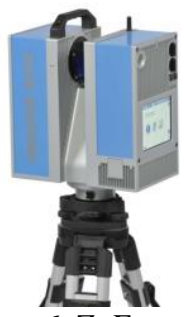

Figure $6 . \mathrm{Z}+\mathrm{F}$ scanner

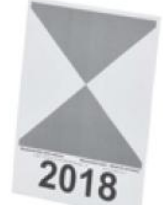

Figure 8. paper target

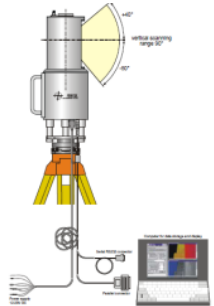

Figure 7. Riegl scanner

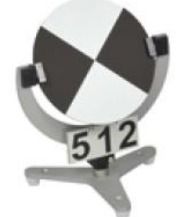

Figure 9. special target for $\mathrm{Z}+\mathrm{F}$
4.1.3 Field Work Scanning: The IMAGER 5006 system $(\mathrm{Z}+\mathrm{F}$ scanner) has been selected for the field work of this project for its portability and the scanner angle of its echo signal receiver. The roof scanning stations (Riegl scanner) are usually set up on the top of the high-rise buildings. The setting up of the scanner relies on the layout of the targets on the historical building and also on the characteristic of the building. The targets of the high-rise buildings should be set on the concave-convex structure perpendicular to the scanning stations

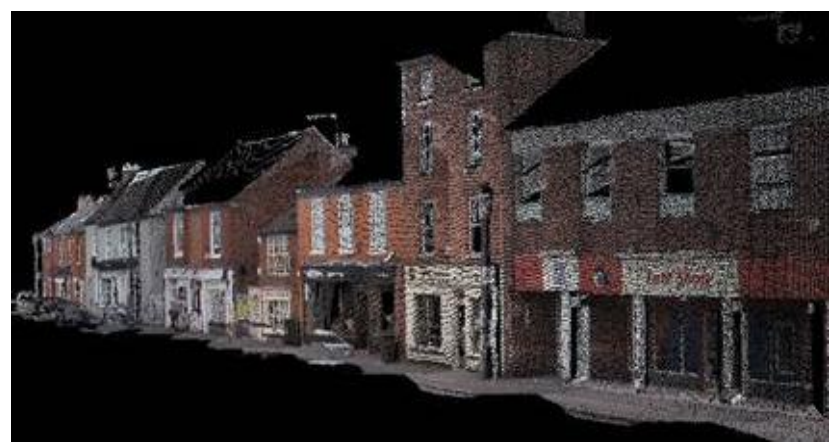

Figure 10. Point cloud data of buildings along the street

4.1.4 Scanning of Historical and Cultural Relics: The accuracy of the scanning for historical and cultural relics is of most importance; the scanning stations should be approximate $15 \mathrm{~m}$ apart, the point clouds density to be $1 \mathrm{~cm}$, data tolerance to be $1 \mathrm{~cm}$. Apart from the data collected from the elevation, scanning was also carried out for the structure of the building and its interior. The internal scanning was done with the IMAGER 5006i.

4.1.5 Setting Up of the Fixed Target Network: At the last stage of the project, fixed target network are set up for continuous monitoring of the historical building where data were collected from varies periods. As the targets are mounted on the exterior of the building, subject to the natural corrosion of harsh weather, tough aluminium alloy was used. To minimize the visual impact to the relics, the size of the targets was minimized. For long term monitoring, temporary targets were also employed.

\subsection{Post Data-Processing}

4.2.1 Data Registration for 3D Scanning Point Clouds: After all the data are collected by each scanning station independently, they are spliced together to form a unified coordination system.

4.2.2 Colour Attribution of 3D Point Clouds: Matching the location of the camera and scanner or the characteristic of the point cloud data with the angle of the image and the spatial relationship of the point cloud data, the image colour can be attributed to the relevant point clouds. The point clouds can then carry their own RGB information.

\subsubsection{D Modeling}

\subsection{The Standard of LOD (Level of Detail) Point Cloud Data Acquisition and Processing}

4.3.1 Overall Features of Urban Sector: The Standard of LOD mainly consists of the scanning data of the building roofs and street facades, registering the roof heights, sizes and shapes of the buildings, dimensions and forms of neighbouring rooflines. For the street facades; information of the skyline, individual building elevations, storey heights and eaves details are collected. From these cloud point data a simple model is constructed.

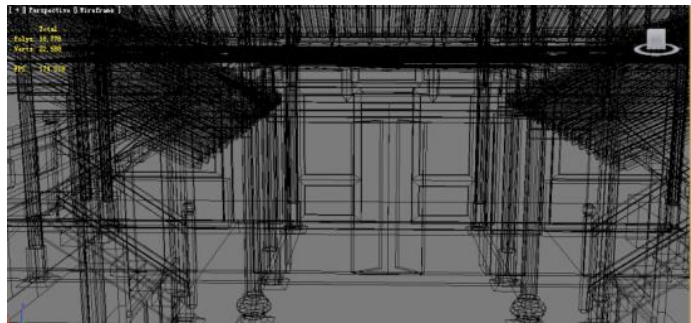

Figure 11. The simple wireframes of the models based on the point cloud data

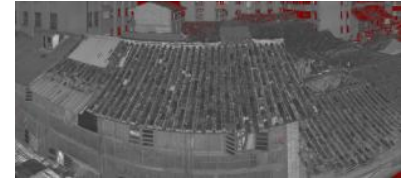

Figure 12. The twodimensional (2D) point cloud of the roof

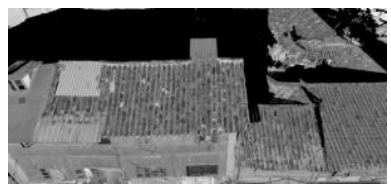

Figure13. The threedimensional (3D) point cloud of the roof 
4.3.2 Different Architectural Types: The buildings in the Wenming Street Historical and Cultural Block in need of preservation can be broadly classified into three different categories; buildings with cultural significance, notable historical buildings and preapproved historical buildings and lastly traditional buildings. With these classifications, the detail of scanning and the final results for the Wenming Street project is also treated under three grades:

a. Buildings with cultural significance; 3D models with colour point clouds with details for the interior and exterior of the buildings.

b. Notable historical buildings and preapproved historical buildings; 3D models with façade and roof for the buildings.

c. Traditional buildings; simple block models recording information of the size of the building including the eaves, storey heights, span and depth of the buildings. Elevation drawing is pasted on to reflect the actuality of the building.

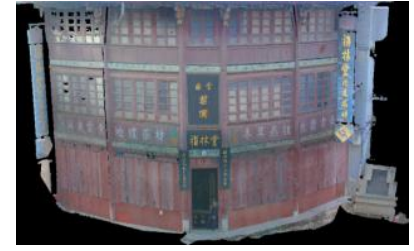

Figure 14. The color point cloud model of the building of Fulintang in Wenming Block

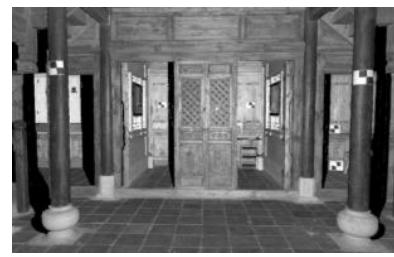

Figure 15. Color point cloud model of the Former Residence of Nie'er in Wenming Block

\subsection{Application of Different Type of LOD Model Data in the Preservation Planning}

4.4.1 Basing on the overall townscape, cloud points of rooflines and street facades, simple wireframe models are constructed. These models can be used to counter check the completed renovated works or to evaluate preliminary proposals on their workability. The ability to see the overall picture at any time is a great tool for preservation planning.

4.4.2 The 3D model forming a part of the preservation program would be the source of the information for the production and alteration of architectural drawings. This would form the basis for the further restoration and supervision, such as the roofing, facades, eaves, doors, window, dougong, carvings, internal staircases and railings, enabling the authenticity of the restoration. For the buildings that have suffered from the lost authenticity due to previous renovations, the 3D models would form a guideline for rectification work.

4.4.3 The 3D models of the notable historical buildings and the preapproved historical buildings recorded information of the roofing, façades, eaves, windows, doors and dimensions of the townscape. This information provides a guideline for the preservation of the cultural historical urban sector, reinforcing the ensuring the authenticity of the restoration.
4.4.4 The townscape of the cultural historical urban sector is formed mainly by traditional buildings, buildings which carry Chinese architectural elements. Such buildings have a lower preservation priority than the buildings with cultural and historical merits. These buildings are safe from being demolished and their architectural features will be preserved, such as the building mass, roofing, eaves, storey heights, material and colour scheme. The characteristic of these 3D models and their elevation would provide information to ensure the authenticity of further renovation works.

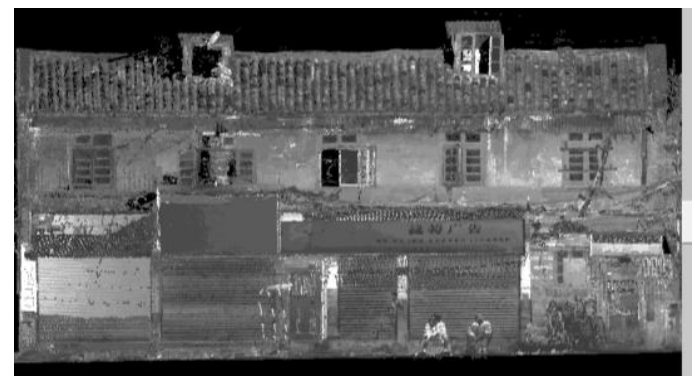

Figure 16. The point cloud data of the front elevation of No.118-124 in the Confucian Temple Straight Street in Wenming Block

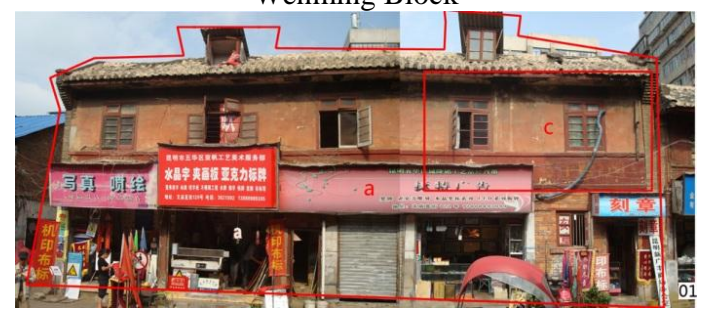

Figure 17. The photograph of the front elevation of No.118-124 in the Confucian Temple Straight Street in Wenming Block

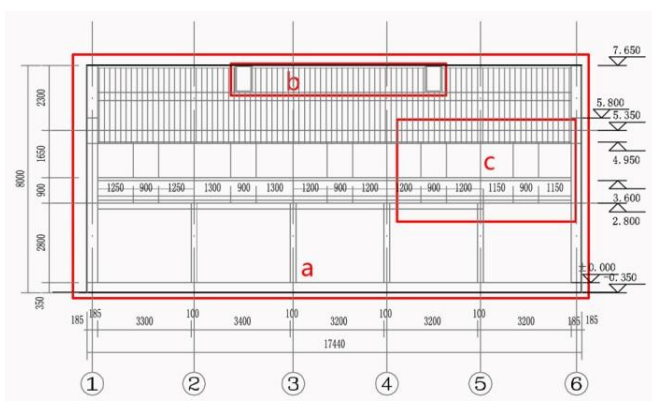

Figure 18. The control drawing of the front elevation of No.118-124 in the Confucian Temple Straight Street in Wenming Block

\section{DATA INTEGRATION}

\subsection{Historical and Cultural Block Basic Informational Platform (HCBBIP)}

HCBBIP is constructed by integrating the structure of HCBIRS and the database produced by the system. As the database is defined by original grid coordinate of CAD file of the block, it is necessary to be converted to local coordinate of Kunming through certain conversion parameter 。 


\subsection{Data packing and spatial matching}

WGS-84 coordinates of the block were obtained by using the Real Time Kinematic (RTK) and total station, and were converted to local coordinate of Kunming for 3D model data through certain conversion parameter. The 3D model data, together with relative historic maps, old photographs and remote sensing images, were spatial matched with and integrated into HCBBIP.

\subsection{The next stage}

The website of Historical and Cultural Block Preservation and Monitor System (HCBPMS) is currently being constructed. The users of website, which contains local government, planning and design staff, district residents and other stakeholders and the public, will be classified into different groups, whom were provided different permissions.

\section{CONCLUSION: TECHNOLOGICAL ADVANTAGES AND APPLICATION PROSPECT}

There are enormous technical advantages and broad prospects for the application of HCBPMS in the preservation and supervision of historical and cultural blocks.

\subsection{Aided plan and design}

The uses of basic information and 3D model data of block can provide accurate and comprehensive information basis for preservation zoning and renovation design alternatives, and provide assists and supports for the planning and designing works.

\subsection{Renovation result checking}

Advantages of high precision of 3D model data could be helpful for checking whether the renovation results are consistent with the original planning and design scheme after the renovation project's completion.

\subsection{Archives management and query}

The use of geographic information databases could realize the digital and networking management of the block preservation and supervision documents, so that, the reliability and convenience of the data management, update, and query could be improved.

\subsection{Dynamic monitoring}

HCBPMS can provide an important basis for block supervision. Supervisors are able to download all the data to handheld devices (iPAD), including topographic map, building evaluation, property right, function, photos and 3D model and so on. When find the suspicious construction by comparison and supervision at scene, they could photograph and feedback to the central database. Supervision departments could regularly do complete update and survey (collect information), and also query and analysis the historical dates by handheld devices and PC client.

The fixed target system forms part of the preservation elements of the Historical and Cultural Block. Periodic scanning collects 3D data for the continuous dynamic monitoring of the preservation area.

\subsection{Digital tourism guide}

The GIS data and 3D model data on HCBPMS could be used to aid museum design, tourism website construction, block virtual navigation APP software development, and to realize the block digital tourism guide.

\section{REFERENCES}

Yisan Ruan, Jinghui Wang, Lin, Wang, 1999. The Preservation Theory And Plan Of Historical And Cultural City. Tongji University Press, Shanghai, pp. 1-11.

Gong Zhang, Xiaowei Huo, Jie Zhang. Digital information acquisition and dynamic supervision system of traditional architectures in historic city/town/village/block--based on the mobile GIS platform. Transformation And reconstruction-China Urban Planning Annual, 2011. Southeast University Press, Nanjing.

Yaning Yan, Wenbin Yang. 2012. Integrated Management and Application of the Digitization of Cultural Heritage, The 2012 International Conference On Digital Applications In Cultural Heritage, Taichung. pp. 183-194. 